\title{
See-Hear-Do Versus Read-Do-Research: An Examination Of An Alternative Method Of Instructional Delivery
}

Bill Francisco, Austin Peay State University, USA

Thomas G. Noland, Georgia Southern University, USA

Debra T. Sinclair, Georgia Southern University, USA

\begin{abstract}
One of the primary course delivery techniques has been the See-Hear-Do model. Under this system, the professor goes through the material and prepares a lecture for the class. The material is then presented to the students, typically using PowerPoint or some other visual graphics. The students are then asked to engage in some exercises, either in or outside of class, and replicate what the professor has performed. In an effort to improve student learning, this paper describes an alternate approach to instruction - the Read-Do-Research Model. The Read-Do-Research model does not involve extensive lectures or require slides. Instead, the students are required to "dig out" what they need to solve the problems. While this method may seem foreign to many educators, it is the position of this paper that this may be a far superior method of student learning when compared to the conventional approach.
\end{abstract}

Keywords: Bloom's Taxonomy, Experiential Learning Model, student centered learning

\section{INTRODUCTION}

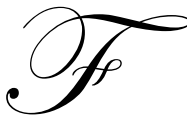

or years educators have been trying to improve student learning. One of the primary course delivery techniques has been the See-Hear-Do model. Under this system the professor goes through the material and prepares a lecture for the class. In addition to the lecture, some type of visual graphics explaining the material is prepared, usually using overheads or Power-Point presentations. Then the students are asked to engage in some exercises, either in or out of class, which have the students replicate what the professor has performed.

This paper will describe an alternate approach to instruction. The Read-Do-Research model does not involve extensive lecture or slides and requires students to research or "dig out" what they need to solve problems. While this may seem foreign to many educators, it is the position of this paper that this may be a far superior method of student learning when compared to the conventional approach.

The main attribute of the Read-Do-Research model is it changes the course from an instructor-teacher as the center of attention to a student-learner centered class. The focus of our method is on teaching the student to be a good learner rather than requiring the teacher to be an excellent lecturer.

\section{SEE-HEAR-DO}

The See-Hear-Do model is instructor centered. The quality of the education is in large part due to the preparation and delivery of the materials by the instructor. The focus behind this approach requires that the professor go through the materials and highlight what they think are the most relevant topics. The onus is on the instructor to find a delivery method better than the textbook author to demonstrate the material. In other words, the instructor's job is to read, summarize, restate and reorganize the basic information in the text. Once this is done, the professor is charged with presenting the material and answering any questions that may be asked during the 
presentation. The final step is for the instructor to provide an assignment to see if the student has grasped the knowledge of the material or concept being covered. The student's knowledge of the material is then tested to see if he/she grasps the instructor's "take" on the material.

You will notice from the proceeding discussion that the instructor is the center of the learning universe and the subject matter mastery is a function of the instructor's ability to synthesize data and disseminate that data to students. The student's job is to absorb what the instructor has compiled and, basically, apply it to situations of the instructor's choosing. This often leads to questions such as, "Do I need the book for this course?" or "Is this going to be on the test?"

Since the student is merely the recipient of the instructor's review, assimilation, restatement and dissemination of the information, there is no reason for the student to assume that anything that is being presented is of any value outside of the current topic. Very often students find that relating the material covered to other situations is a task they cannot handle. Remembering and using the data at a latter date and integrating the material into other situations often proves to be a pointless task because understanding the interconnecting relationships outside of the frame of the individual topic covered are not comprehended by the student. The student finds the relationships to other situations not specifically covered by the instructor hard to visualize. This limited understanding is one of the main reasons for the often heard criticism that students do not know how to problem solve.

It is our premise that the problem is not with the student's inherent ability to solve problems but with the integration of that knowledge into an unknown set of circumstances. The reason for this is that the students have had their knowledge distilled by an intermediary, the professor, and the analysis and synthesis of that knowledge not related to an objective outside of the "Do" component of the professor's requirement is not necessary.

Figure 1 shows how information is generated and passed from professor to student. As you can see, information is designed and disseminated by the professor with minimal input from the student. The focus is almost totally based on the instructor's contribution. Students are left to be passive bystanders to their own education.

Figure 1: See-Hear-Do Model

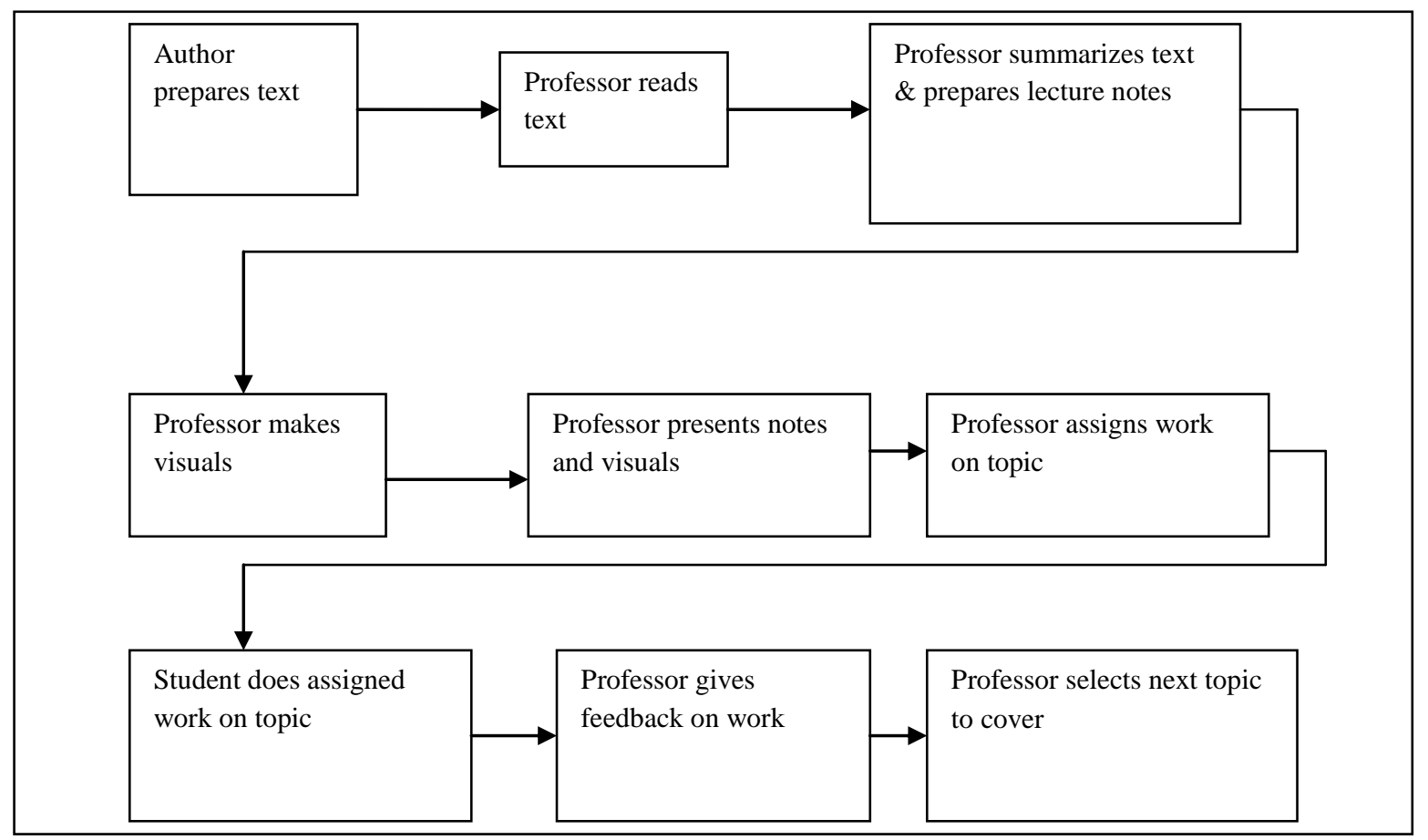


Why has this situation occurred? In many universities there has developed a mantra for good teaching. Administrators cry for professors to become better teachers, but there seems to be no consensus on what constitutes better teaching. Rather than coming up with improved teaching methods and training of professors, many universities have left the definition of better teaching to be answered by students by putting great stock in student opinion surveys. Many universities even go so far as to call these surveys "evaluations of instruction".

The use of student evaluations as a measure of effective teaching is rampant on college campuses. The relationship is thus established that, if one is to be a good teacher, he/she must develop a technique that breaks material down into bite-sized pieces. The student theorizes that the "holy grail" is to accumulate enough of these pieces so that they might recite these pieces back to the professor at test time so that both the student and the professor are satisfied with the result. After this objective is achieved, the professor moves on to the next topic. Often relationships of the material being studied to other topics are ignored and alternate uses of the knowledge are not discussed.

The key missing ingredient is how this knowledge can be used. Being rational consumers, the student assumes that those professors who make the clearest demands of what is expected are the best teachers. Instructors who can make the process the easiest to master are, in the student's eyes, the premier professors. The problem is that "mastery" is considered by the students who complete evaluations as the ability to recite and apply a few facts the professor has deemed pertinent. Students are seldom asked to apply those principals to differing facts under unspecified circumstances, and professors are afraid to ask these more challenging questions because such requests are deemed "trick" questions.

\section{BLOOM'S TAXONOMY}

It is our goal to move the student from an Application level of learning, as defined by Bloom's Taxonomy of Cognitive Learning, to an Evaluation level (see Table 1). In order to move students to a higher level of learning, a radical redesign of the learning model must occur. Students will only improve their problem-solving skills when professors require them to take "ownership" of their education.

\section{Table1: Bloom's Taxonomy of Cognitive Learning Levels}

KNOWLEDGE - This is the lowest level of learning. It includes recall and memory.

COMPREHENSION - Students use facts or ideas without relating them, which reflects a literal understanding of the topic.

APPLICATION - This is the intellectual skill that entails use of information in specific situations. Information may be in the form of general ideas, concepts, principles, or theories that must be remembered and applied.

ANALYSIS - This skill involves taking apart information and making relationships in order to discover the hidden meaning and the basic structure of an idea or fact. The student is able to distinguish between fact and opinion and to assess

consistency.

SYNTHESIS - The student is able to reassemble the component parts of an idea in order to develop new or creative ideas.

EVALUATION - This is the highest level of cognition. It involves making judgments on materials, information, or methods. In problem solving, it involves selecting among competing alternative solutions.

(These were taken from the article "Restructuring the Accounting Curriculum Content Sequence: The KSU Experience" by Penne L. Ainsworth and R. David Plumlee in the Spring 1993 issue of Issues in Accounting Education, p. 118.) 


\section{EXPERIENTIAL LEARNING MODEL}

Our Read-Do-Research model is based on the experiential learning model that is widely-used at the U.S. Army Command and General Staff College. The Army's Command and General Staff College (CGSC), a fully accredited graduate school, executes professional military education programs through five educational institutions: Command and General Staff College, School of Non-Resident Studies, School of Advance Military Studies, School for Command Preparation, and the Army Management Staff College. The underlying tenet of the CGSC philosophy is that their students are adult learners that must learn from an active rather than a passive approach to education. The philosophy utilizes Dr. Malcom Knowles' (1993) conditions for learning as a foundation. Knowles' philosophy includes the conditions that learners actively participate in the process and that learners accept a share of the responsibility for planning and developing a learning experience.

The CGSC's experiential learning model consists of a five-step framework that is based on Dr. David Kolb's theory of four methods of learning. Kolb's methods include: concrete experience, reflective observation, abstract conceptualization, and active experimentation. The Command and General Staff College has taken Kolb's (1984) four methods and broken them down into five phases: concrete experience, publish and process, generalize new information, develop new courses of action, and apply courses of action.

The concrete experience addresses learning objectives from personal involvement. Students learn by feeling rather than thinking. An example of the concrete experience is to give the students a quick case study about fraud at a corporation. Then, after the students have had time to read the case (whether in class or as a take home assignment), the publish and process phase begins. For example, the instructor could ask the students what happened and how they "feel" about the CEO going to jail for the fraud. The key learning will take place as all members of the class share their thoughts with the group.

The generalize new information phase is similar to the traditional lecture format. The instructor is the "sage on the stage" and delivers new content to the students. This phase should be limited and concentrate on only the more complex topics that students might find difficult to understand.

The develop new courses of action phase is where students go from abstract theory to application of the theory. Students will have to decide how to apply the learning and deal with "what ifs". The instructor can give open-ended questions and problems that require critical thinking. In an accounting context, think of the calculation of earning per shares (EPS) as example of what ifs. While the student realizes they must be able to calculate EPS, the student must understand all the various accounting estimates that go into the underlying net income figure (think bad debt expense, inventory write-downs, depreciation expense, amortization expense, etc.). Once the students understand the number of estimates that go into the EPS calculation, they can then understand how easily the figure can be manipulated.

The final phase of the CGSC experiential learning model is apply courses of action. This requires students to perform practical exercises. The practical exercises are completed by the students and evaluated by the instructor. To maximize learning, the practical exercises should be completed in a group in order for students to learn from each other. However, it is imperative that the instructor emphasize that, at some point (think mid-term or final exams), the students will have to demonstrate their individual "mastery" of the topic by utilizing their analysis, synthesis, and evaluation skills.

\section{READ-DO-RESEARCH}

The Read-Do-Research model refocuses the classroom from an instructor-dominated to a student-centered learning experience. The professor acts as a moderator requiring the students to find the relevant facts in the material. The "do" part consist of students applying the material in a different context than what was presented in the assigned reading material. The "research" component consists of students finding ways to apply what they have learned from both the read and do phases to perform related tasks not directly paralleling the text material. 
The job of the professor changes from that of a proof reader and note taker of the textbook, to a designer of projects and arbitrator of results. The professor's role is to guide students where they have problems, not to make sure they never encounter a problem. The students are forced to use creativity and problem solving skills since projects are open ended and there is usually no one right way to solve the problem. The student must define the problem and find a possible solution that applies to a new set of circumstances. Rote memorization of a formula to solve a particular problem will no longer be enough to pass the class. The basic relationship is as follows.

Figure 2: Read-Do-Research Model

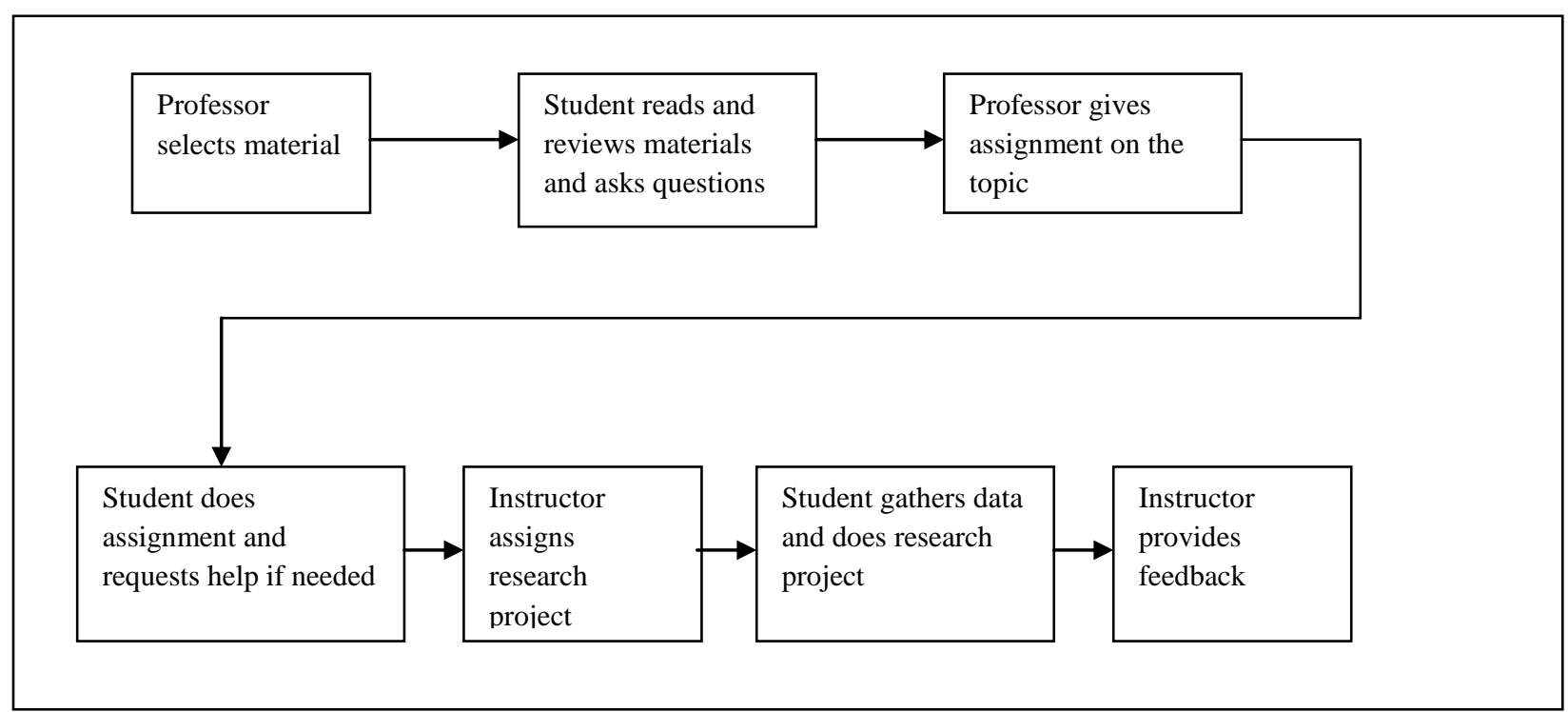

Notice that the Read-Do-Research model (Figure 2) focuses on student-centered learning. The student must determine what is pertinent to solving the problem and how material is interrelated. Students are responsible for determining what information they need to further consider and if an assignment or project is similar to one encountered in prior circumstances. The instructor can identify those difficult topics that the students did not comprehend and go over those areas in class. The Read-Do-Research model also has the added advantage of paralleling how work is assigned in most workplaces. The employee is given a task and asked to solve the problem, typically with little or no instruction. It is important for students to develop these skills which will later be required in the workplace.

The Read-Do-Research model forces the student to reach a higher cognitive level of learning. It is not enough to be able to apply knowledge in a specific situation. The student must be able to analyze and synthesize information in order to evaluate the various solutions that may solve a problem.

\section{SUMMARY AND CONCLUSIONS}

For students to become better problem solvers, they must learn to recognize the problem, consider alternatives, select the best alternative and solve the problem. The current teaching methods do not adequately prepare the students to solve complex problems. The See-Hear-Do model may be an excellent method for training people to perform rote tasks; however, it does little to provide a basis for real-world problem solving.

To be an effective problem solver, students must learn how to define the problem. They must determine which methods and techniques are appropriate under a given set of circumstances. Students must be able to analyze 
and synthesize information. The student must be able to reach into their toolkit and utilize their knowledge to evaluate and solve complex problems.

The Read-Do-Research model puts the emphasis on student learning instead of instructor teaching. While the instructor is still a vital component of the learning process, the student must now take charge of their education. The goal is not to make professors better lecturers but rather to make students better learners.

\section{AUTHOR INFORMATION}

William Francisco is an Assistant Professor at Austin Peay State University and Assistant Professor Emeritus at Georgia Southern University. He has over 30 years of teaching experience in higher education. Prior to entering academia, he worked for a large defense contractor. Bill holds professional certifications as a Certified Public Accountant and Certified Management Accountant. Bill also served as a member of the Bulloch County Georgia Board of Education.

Thomas G. Noland is an Associate Professor at Georgia Southern University. Tom is also a Lieutenant Colonel in the Army Reserve. He holds professional certifications as a Certified Public Accountant, Certified Management Accountant, and Certified Defense Financial Manager. Tom has served as an Academic Fellow in the Securities \& Exchange Commission's Office of Chief Accountant. Prior to entering academia, Tom was an active duty Army Officer and a Federal Bank Examiner.

Debra Sinclair is an Assistant Professor at Georgia Southern University. Debra has been the recipient of several teaching awards by the College of Business Administration at Georgia Southern. She was also selected by accounting majors as the professor of the year in the School of Accountancy. Debra has earned her Certified Management Accountant designation. Prior to entering academia, Debra worked as a corporate accountant.

\section{REFERENCES}

1. Knowles, Malcolm (1993) The Modern Practice of Adult Education from Androgogy to Pedagogy.

2. $\quad$ Kolb, David A. (1984) The Cycle of Learning Experience.

3. Risner, Rhoda and Thomas E. Ward (2007) Concrete Experiences and Practical Exercises: Interventions to Create a Context for a Synergistic Learning Environment, Working paper. 